\title{
ENTREVISTA COM MIGUEL CARTER
}

\author{
INTERVIEW WITH MIGUEL CARTER
}

\section{Por Laura Schühli*}

Colaborou nesta entrevista: Antonio Carlos Senkovski, Bacharel em Comunicação Social, habilitação em jornalismo, pela Universidade Positivo, e graduando do Curso de Filosofia, na Universidade Federal do Paraná.

Curitiba, 24 de novembro de 2010.

Durante o lançamento de seu livro "Combatendo a desigualdade social: o MSTe a Reforma Agrária no Brasil", o professor da School of International Service da American University, Miguel Carter, concedeu entrevista sobre os principais temas que atravessam sua trajetória intelectual há quase duas décadas e reemergem na obra de que é organizador: a ação política dos movimentos sociais, a Reforma Agrária, o papel do direito e do Poder Judiciário, os aparelhos ideológicos da mídia de massas, o lugar da Amazônia num novo projeto social e os desafios para ceifar a desigualdade social e a má distribuição de terra e de renda no país.

Carter nasceu em Patzcuaro, um povoado mexicano, cresceu no Paraguai e mora hoje nos Estados Unidos, mas por anos esteve no Brasil, com olhos atentos para a questão fundiária e as peripécias da democracia em toda a América Latina. Doutor em Ciência Política pela Columbia University e pós-doutor pela University of Oxford, conjuga a preocupação com solidez dos dados empíricos e uma opção ético-política clara: "Sempre temos uma escolha, a minha é pelos direitos humanos, pela democracia e pela justiça social, são esses meus grandes princípios norteadores". E confessa: "eu sonharia em ser metade camponês e metade intelectual".

No presente trabalho, reuniu textos de 19 consagrados autores, entre eles Bernardo Mançano, Horácio Martins de Carvalho, George Meszaros e Plínio de Arruda Sampaio,

* Jornalista, pós-graduada em Jornalismo Literário pela Associação Brasileira de Jornalismo Literário/ Faculdade Vicentina. Atua como assessora de comunicação da OrganizaçãoTerra de Direitos e da rede Plataforma Dhesca-Brasil. 
os quais se debruçaram sobre o papel e as perspectivas dos movimentos sociais na luta pela efetivação de direitos.

\section{1 - Neste seu trabalho, sobressai em diversos momentos uma certa} ênfase em destacar que, a despeito da relevância da ação dos movimentos sociais como um todo, a atribuição final pela realização da Reforma Agrária é do Estado. O senhor poderia abordar um pouco mais essa ideia? O que o leva a adotar essa visão?

A ideia de Reforma Agrária sempre teve por conotação uma mudança na estrutura agrária, na estrutura fundiária, e quem faz isso tem de ser a autoridade. Nas sociedades modernas, essa autoridade é o Estado. Ainda em sociedades antigas, podia ser - e era de fato - realizada pelo equivalente ao Estado, o que foi repetido também em outros períodos. Séculos antes de Cristo já houve experiências de mudanças nas leis agrárias e decomposição da propriedade. A Revolução Francesa significou uma nova era para a questão, mas ela sempre foi conduzida, de uma forma ou outra, pelo Estado. Contudo, a Reforma Agrária não acontece se não houver demanda, o Estado não vai agir sem algum sinal de que isso é uma necessidade, uma expectativa, de que isso poderia solucionar problemas concretos da sociedade existente. Então o que ocorre é que existe uma certa dinâmica dialética, em que o Estado é o árbitro final que determina essa distribuição da terra e a sociedade organiza, em diversos graus de eficácia ou de visibilidade pública, a demanda. Movimentos sociais como o Movimento dos Trabalhadores Rurais Sem Terra [MST], os grupos que participam desse movimento mais amplo da luta pela reforma agrária no Brasil, o que fazem é tornar essa demanda visível, ajudando a organizá-la. E numa sociedade cada vez mais complexa, como é a nossa na América Latina do início do século XXI, requer-se que as organizações que assim atuam tornamse também mais complexas e sofisticadas. Daí, portanto, a longevidade do MST, dada a sua grande sofisticação como movimento que já não somente luta por terras, mas também por um outro modelo de desenvolvimento rural e tem bandeiras que vão além disso, que contestam as forças dominantes do próprio processo de globalização, contestam certos hábitos e certas formas de enxergar a civilização em si, no sentido de buscar que ela se torne mais sustentável, ligada igualmente a valores ambientais e ecológicos.

2 - O senhor tem feito recurso, porém, a um conceito instigante de "reforma agrária conservadora". Poderia explicitá-lo?

O que tento diferenciar são dois modelos de reforma agrária nos regimes democráticos atuais. A conservadora é aquela que tem predominado no Brasil, uma reforma agrária feita à base de pressão social. Ela responde apenas, não se adianta à 
demanda, ela é contida, não procura reformar a estrutura, mas tenta apaziguar os conflitos que existem em diversos pontos do país. E é uma reforma que se relaciona simultaneamente com o status quo, com a elite agrária dominante, de uma forma que não atinja seus interesses. Se for necessário indenizar a propriedade, isso sempre se faz de forma que a elite fique muito bem recompensada, seja porque os indicadores que o Estado utiliza para valorar a terra geralmente vão além do preço do mercado, seja porque o Judiciário acaba favorecendo essas elites ao conceder valores muito mais altos que os convencionais. Nesse sentido, ela é uma reforma agrária que se desenvolve numa relação, no máximo, paternalista com os movimentos sociais, ou de embate com os setores que procuram alterar mais profundamente a estrutura fundiária. São recorrentes as violações de direitos humanos nesse processo e há muita impunidade, em relação aos assassinatos de lideranças e sujeitos envolvidos na luta pela reforma agrária, e uma relação com os assentamentos que se limita a repassar recursos quando há pressão ou cobrança intensa dos movimentos envolvidos. Sem muita preocupação, por exemplo, com outro tema que entendo fundamental no século XXI, isto é, a agroecologia. Enquanto uma Reforma Agrária progressista faria o contrário, ela trabalharia bem com a demanda social, aproveitaria essa demanda para promover uma mudança estrutural. Teria também uma visão mais ampla do que seria essa mudança, a partir de políticas que procurassem fortalecer a classe camponesa, a agricultura familiar. Haveria, neste caso, políticas estruturantes que iriam ao encontro de fortalecer os trabalhadores rurais como um todo e de não mais subsidiar a elite agrária, que sempre ficou com o grande miolo do dinheiro que é investido no campo por parte do Estado. Então seria possível pensar num conjunto de ações que teria outro objetivo, já não trabalhar a reboque dos movimentos sociais, mas trabalhar com os mesmos a partir da sua energia, da sua mobilização. Eu diria que na experiência brasileira, alguma ilustração do que poderia ter surgido nesse campo mais progressista teria sido o governo Lula, caso tivesse aceitado o programa do Plínio [de Arruda Sampaio para a Reforma Agrária]. E foi basicamente por medo da elite agrária que isso não foi aproveitado. A Reforma Agrária conservadora tem como uma das marcas esse medo de mexer com as elites, a ausência de vontade em enfrentá-las, evitando o confronto com esses setores poderosos e, ao fazer isso, acaba optando mais pelos seus interesses, direta ou indiretamente, do que pelos interesses da classe camponesa e da pequena agricultura familiar.

3 - 0 senhor afirma que a responsabilidade pela reforma agrária é fundamentalmente estatal. Ao mesmo tempo, indica as limitações desse processo no contexto de Executivos que o subordinam a interesses das elites agrárias. A partir de suas pesquisas, é possível tambpem identificar, de maneira geral, o papel do direito e do Poder Judiciário nisso? 
O capítulo do livro escrito por Meszaros [O MST e o Estado de Direito no Brasil] faz uma análise interessante de como os setores populares começaram a olhar a lei como um instrumento, não só defensivo, mas também positivo para questionar a tremenda grilagem de terras que aqui existe e as violações das leis trabalhistas e ambientais como um elemento de luta e de pressão para conseguir que essas propriedades sejam passíveis, por determinação constitucional, de destinação para a reforma agrária. O que o autor mostra, em suma, é que no decorrer dos últimos 25 anos, sua relação com a lei foi se modificando. Mesmo com os problemas tradicionais de lentidão e burocracia, subsiste a ideia de que as esferas legal e judicial também são um campo de batalha. Enfim, o sentido e o propósito mesmo da lei têm de ser alvo de um debate mais amplo, de uma disputa de hegemonia em torno dessas questões, o que fazem os movimentos sociais quando se perguntam: "para quem está funcionando bem a lei existente?". O interessante é ver que normalmente se caracteriza um movimento como o MST como sendo contrário à lei, um movimento que violentaria a lei. O MST faz isso apenas em parte, justamente porque as leis são muito rígidas e criminalizam os grupos que tentam contestar a estrutura fundiária. Mas, ao mesmo tempo em que entra em choque com a lei, ele é um movimento que participa do esforço para mudar uma determinada estrutura legal ou as concepções legais que existem no Brasil. Nesse sentido, o MST é semelhante a outros movimentos sociais: o movimento operário, das mulheres, o movimento gay, que no seu tempo também tiveram embates com a estrutura da lei e com o Poder Judiciário. As greves eram ilegais, os sindicatos eram ilegais, eles se organizaram, produziram enfrentamentos e conseguiram mudar a lei. Então os movimentos sociais não só sempre entraram em conflito com a lei, mas também devem que ser vistos como arquitetos de uma nova ordem jurídica. É isso que, creio, é preciso sublinhar: que não se trata apenas de uma questão de embate, mas também de criação de novas formas de conceber e de fazer as leis. E de novas leis que possam de fato atender aos interesses e direitos de grupos hoje desprivilegiados.

\section{4 - Embora o MST seja um movimento social que conquista avanços para} o exercício da democracia no Brasil, existe contra ele ainda um forte preconceito da sociedade e por parte mesmo de alguns setores do Estado, um medo contido quando nele se fala. A imprensa tem uma parcela de responsabilidade na construção desse conceito terrorista sobre o MST no Brasil?

Sem dúvida. O problema é que no Brasil o latifúndio não é só de terra, existe um latifúndio midiático. São nove conglomerados, a maioria deles familiares e um deles vinculado à Igreja, que produzem, segundo estudos como os do site "Donos da Mídia", 85\% das informações veiculadas nesses meios. Vale dizer, são grandes conglomerados vinculados, em maior ou menor grau, à elite agrária, financeira e industrial. E é evidente a falta de espaço para retratar aspectos positivos ou alternativos sobre os movimentos 
populares, e não apenas sobre o MST. Esse latifúndio midiático acaba distorcendo de uma forma incrível essas questões, sinto dissonância cognitiva quando eu participo de alguma atividade como pesquisador, junto ao MST, e depois vejo como esse mesmo evento é retratado na imprensa. Vejo uma coisa, sou testemunha dela, e depois leio algo completamente diferente. Posso dar exemplos, como a revista Veja, que tem uma atuação claramente com o objetivo de difamar o MST. E eles não abrem espaço algum para que um pesquisador possa analisar o movimento sob uma outra óptica. Um exemplo concreto disso: em 2004 fui contatado por um repórter da Veja que fazia uma matéria sobre a nova geração de brasilianistas na academia norte-americana. Muito simpático, disse-me que várias pessoas me haviam indicado para falar sobre a questão agrária no Brasil. Tivemos longas conversações, mais de uma, trocamos materiais, passei a ele muita informação, ele pareceu entusiasmado. Duas semanas depois o mesmo repórter me liga, "professor vou ter que me desculpar, queria fazer muito matéria sobre suas pesquisas, só que meu chefe disse que não temos espaço para isso". É evidente que eu fui censurado na Veja, que tanto prega liberdade. E por que motivo? Porque não se podia divulgar a existência de pesquisadores sérios, rigorosos, com grande familiaridade e experiência no campo, com um olhar diferente daquele pregado pela Veja. Esse para mim é um exemplo marcante. Ora, a grande imprensa tem jogado assim, especialmente na última década. Logo depois do Massacre de Eldorado dos Carajás havia ainda algumas reportagens que destacavam as arestas. Mas depois que o governo Fernando Henrique Cardoso, no ano 2000, começa a ter um embate mais duro com o MST, e com a reação do movimento a esse mesmo governo, houve uma opção, desde o Palácio do Planalto, em trabalhar com a imprensa para cercar determinadas pautas. Desde 2000, acredito ter-se estabelecido uma relação muito mais hostil por parte da imprensa com os movimentos sociais. Eu diria, inclusive, que, no primeiro governo de Lula, o objetivo dessa grande imprensa era o seguinte: fazer uma marcação dura contra o MST para "cortar as asas" da esquerda do PT dentro do próprio governo Lula, uma forma de tentar enquadrá-lo e torná-lo um governo que não atrapalhasse o interesse da elite agrária e de outras elites a ela vinculadas no Brasil.

4 - Imprensa e Judiciário aproximam-se, de certa forma, porque funcionam ou tentam funcionar a partir da premissa da neutralidade e da imparcialidade. Assim como também a academia, onde o senhor desenvolve suas pesquisas. $O$ senhor consegue perceber que o conceito da imparcialidade, de fato, baliza o espaço dos trabalhos acadêmicos?

Há neutralidade e não há neutralidade. Eu não acredito que o objetivo último de uma pesquisa e sua contribuição para a sociedade seja neutral. Sempre temos uma escolha, a minha é pelos direitos humanos, pela democracia e pela justiça social, são 
esses meus grandes princípios norteadores. Então, espero que minha contribuição acadêmica possa servir para fortalecer os direitos humanos, aprofundar a democracia e criar condições para um país mais justo, não só no Brasil, mas em meu país, que é o Paraguai. Nesse sentido, não sou neutro. Já quanto à apuração dos dados, na busca por ouvir fontes diversas, no cuidado empírico ao questionar os números, e na preocupação de deixar transparecer os métodos como calculo os assentamentos, por exemplo, há um rigor objetivo e neutral. Os meus números são os números que efetivamente encontro, faço um trabalho muito rigoroso, empírico.

Agora, se buscamos uma imprensa democrática, ela deve buscar formas de aprofundar a democracia. Se o Judiciário está a serviço da democracia, tem que aprofundar as relações democráticas e as condições que permitam que essa democracia progrida e se expanda para além de uma democracia de baixa qualidade, como existe, grosso modo, no Brasil. Uma democracia que funciona para algumas coisas, mas que para a efetivação dos direitos de cidadania da maioria dos cidadãos está longe de ser igualitária, quero dizer, dos direitos realmente vividos na experiência cotidiana das pessoas. Daí o desencanto com a classe política brasileiras, com as muitas instituições que existem nesse país.

Por sua vez, o Poder Judiciário, se for democrático, tem que eleger um certo norte, já não se pode esquecer que ele funcionou muito bem também durante a ditadura militar. Ainda existem juízes que não necessariamente por integrarem o Judiciário pósConstituição de 1988 são democráticos. Da mesma forma, há leis e normas que, mesmo participando de um regime democrático, não favorecem a democratização ou o avanço da democracia no Brasil. Não podemos esquecer isso: o Judiciário também funcionou muito bem no regime autoritário.

\section{5 - Sobre desigualdade e pobreza, o senhor menciona, no livro, que} ambos não são "inerentemente relacionadas". Gostaríamos que abordasse esse tema, especificamente com referência à questão agrária, já que tem papel central na manutenção da desigualdade e na geração viciosa da pobreza.

É impressionante como ainda encontramos essa crença em Washington, nas grandes agências do Banco Mundial, pessoas que acham que desigualdade e pobreza são a mesma coisa. Isso não é verdade. Uma coisa é você ter um grande segmento da população que não consegue nem mesmo se alimentar devidamente, que não tem teto, que não tem segurança mínima - o caso da extrema pobreza. Outra coisa é você ter uma sociedade em que as condições são tão desiguais, a distribuição de renda - de riqueza no sentido mais amplo, de terra, por exemplo - é tão injusta que cria uma série de outros desequilíbrios na dimensão do acesso a recursos públicos. 
Explico isso na introdução do livro. Porque é possível uma sociedade relativamente próspera, como os Estados Unidos, mas que hoje tem patamares de terceiro mundo de desigualdade. O que aconteceu, desde o governo Reagan para cá, é uma coisa impressionante, uma sociedade que tinha a classe média forte e se estagnou. Os EUA seria um bom exemplo de sociedade rica, mas com um incrível padrão de desigualdade. O Brasil, a seu turno, é um país que conjuga as duas coisas. É um dos mais desiguais do mundo e ao mesmo tempo tem ainda uma camada ampla de pessoas extremamente pobres. É verdade que tem menos miseráveis, hoje, mas ainda congrega uma camada social com padrões mínimos de consumo. Trata-se, nesse caso, de sociedades cheias de tensões - desde a criminalidade às disputas sociais - que se manifestam num mal-estar social com a classe política e com boa parte da institucionalidade política. Quer dizer, no Brasil - basta observar os dados - só $10 \%$ da população acredita que se tem um julgamento justo no Poder Judiciário, uma descrença enorme. Esses são levantamentos feitos por entidades como a Latinobarômetro. No Brasil, ainda, somente $5 \%$ das pessoas diz ter confiança no próximo, existe um alto índice de desconfiança, o que implica a possibilidade de contar com menos capital social. Isso atrapalha o funcionamento das instituições políticas, até mesmo das relações de mercado. Se não se tem confiança no outro, torna-se mais difícil entabular um contrato, por exemplo, sempre existe o receio de ser enganado. Isso também gera uma maior dificuldade de se associar na própria sociedade civil.

\section{6 - Há pouco falávamos sobre biodiversidade e recursos naturais. O senhor crê que um novo modelo de produção, aliado à situação da biodiversidade na Amazônia pode alterar o perfil de atuação dos movimentos ligados à terra, como o próprio MST?}

Acho que não é só o caso da Amazônia, mas a Amazônia talvez seja a bandeira mais visível. Eu acredito que a grande novidade da demanda por Reforma Agrária e por terra no século XXI passe pela questão ambiental. Inclusive, já podemos começar a falar de uma Reforma Agrária ecológica, porque ela terá que necessariamente incluir esse padrão. É com essa bandeira que os movimentos populares têm talvez a sua maior chance de mudar a correlação de forças e de percepções da sociedade a respeito da necessidade da Reforma Agrária. Porque o agronegócio, com a agricultura desenvolvida em escala industrial de alto consumo de energia, poluição dos rios e uso escalar de pesticidas - o Brasil é já o pais que mais faz uso de pesticidas no mundo, 3,6 litros por pessoa, em média -, enfim, todo esse desgaste ambiental chegará, em um determinado momento, a ser visto como ultrapassado. Essa característica do agronegócio como produção extensiva e com elevado custo, será interpretada como hoje nós vemos as 
fabricas do início do século XX: aquelas chaminés que atiravam fumaça, que até algumas décadas atrás eram vistas como uma coisa moderna. Hoje ninguém quer uma chaminé que jogue fumaça sem parar. Esse modelo de agricultura [do agronegócio] será visto, necessariamente, daqui a uma década ou duas - já está sendo percebido por muitos, mas isso deve começar a se tornar uma visão mais ampla -, como uma forma inconcebível de proceder. E na procura por alternativas, terão que se resgatar elementos do que tem sido a agricultura camponesa, familiar e indígena. E com tecnologias adequadas, não se trata de um retrocesso, de uma volta ao passado. Haverá elementos tecnológicos, ciências aplicadas, conhecimento... mas sobretudo o resgate de valores daquela forma de fazer agricultura. Valores como respeitar a importância do cuidado do solo para gerações posteriores, fazer investimentos em florestas e não só considerar o lucro imediato. Esses movimentos, quando falam da Amazônia do resto do Brasil, estão protagonizando um novo paradigma, uma nova civilização. E a Reforma Agrária, que se tornará viável neste século XXI, vai terá que incorporar essa bandeira. Nessa disputa de modelos, poderemos levantar questões que não estão muito à flor da pele no momento. Pois uma Reforma Agrária ecológica não poderá ser tratada como problema unicamente dos pobres do campo, de quem necessita de acesso à terra, mas também da classe média urbana que quer superar seu modo de vida, que quer ter acesso a uma propriedade no campo. No meu caso, por exemplo, eu sonharia em ser metade camponês e metade intelectual. Ter a possibilidade de escrever, mas ter um espaço onde pudesse trabalhar a terra, cuidar da floresta, ter alguns cultivos e conjugar uma vida de classe média, uma vida urbana, mas morando no campo.

A Reforma Agrária, nessa óptica, já não buscará resolver só o problema da miséria extrema aqui, mas será uma forma de oferecer modos alternativos de vida e criar condições para se viver no campo com acesso à internet, às estradas, à educação e à saúde. Quer dizer, um outro modelo de desenvolvimento urbano-rural, que faz com que a vida no campo seja uma vida prazerosa. Além de ter em torno a natureza, você participa da recriação dela, produzindo, participando de relações de mercado, cooperativas etc., criando condições para um outro tipo de vida. Não é por acaso que na Europa, hoje, há pessoas retornando ao campo, adquirindo pequenas propriedades, criando 20 ou 30 vacas para produzir queijo especializado na França ou legumes orgânicos. Creio que a reforma agrária do século XXI, sendo ecológica, já não significa apenas cuidar dos pobres, ela é também a reinvenção do padrão de vida rural, além de fortalecer as cidades pequenas do interior desde um novo modelo em que boas condições de vida urbana possam ser acessíveis também. Em oposição à sociedade que o agronegócio modela, com todos residindo em grandes cidades e esvaziando o campo para implantar o maquinário necessário a esta agricultura altamente danosa para o meio ambiente. É uma questão de repensar alternativas. 


\section{7 - $O$ senhor gostaria de comentar mais alguma coisa?}

Eu acho que há uma questão central, que é a grande importância dos movimentos sociais - do MST, que é um dos mais expressivos - para a democratização do Brasil, sobretudo tendo em conta a retórica veiculada pela mídia e pelos intelectuais que hoje estão afinados com a grande imprensa, um discurso apropriado pela elite agrária. O tratamento dado ao MST por esses grupos é como se o mesmo representasse uma ameaça para a democracia. Ao contrário, o MST é um movimento que tem favorecido a expansão de direitos e cidadania, tem ajudado a fortalecer a educação e o resgate da dignidade das pessoas no campo. Quem vai a um assentamento do MST encontra pessoas que contarão sua história de vida antes e depois: sua vida mudou, passaram por um processo de conversão de camponeses humilhados a protagonistas da construção de uma nova sociedade. $\mathrm{O}$ que se tem é a construção de dignidade, de consciência política, de conhecimento de seus direitos, de uma nova forma de fazer e de participar da política. Isso em um país no qual esse setor camponês até 1985 era praticamente analfabeto, não tinha direito ao voto, estava proibido de formar associações. Estamos falando de um setor muito apartado na construção dos seus direitos civis e políticos, mas que está se reerguendo. Com isso, o MST contribui de uma forma muito interessante para ampliar o debate público nacional, introduzindo nele novos elementos e perspectivas. E tudo, de certa maneira, desde o ponto de vista liberal - refiro-me a John Stuart Mill, grande precursor do pensamento liberal político. É uma enorme contribuição, porque desconstrói o discurso hegemônico e auxilia a formular um discurso mais amplo. Mesmo do ponto de vista liberal, que defende o pluralismo, isso teria que ser visto como uma coisa valiosa. Porque não há nada pior, ainda no horizonte do liberalismo político, do que um discurso que não aceita, teme a contestação das ideias e dos valores dominantes. $\mathrm{O}$ discurso liberal político, em essência, afirma que quanto mais ideias políticas houver, tanto mais fecundo o debate, melhor para a sociedade como um todo. Nesse sentido, não é nem mesmo preciso adentrar a visão de mundo socialista, basta avaliar o ideal democrático para se concluir pela relevância que tem o MST. E eu acrescentaria mais um ponto: grupos, como o MST, que levantam uma bandeira utópica, que desejam uma sociedade mais justa, mais participativa e com mais liberdade, contribuem de uma maneira fundamental para a democracia. Porque a democracia, se por um lado, é uma realidade, que pode ter suas deficiências, suas limitações, ao mesmo tempo é um ideal, um sonho. Ela abraça grandes valores, como a igualdade, a participação política. Movimentos que fomentam sua dimensão ideal fazem parte do tensionamento entre o ideal e o real, que é, concretamente, o que faz com que a democracia consiga progredir, porque ela é um 
processo inacabado. O aporte do MST, ao tensionar com essas grandes demandas populares por mudanças mais estruturais na sociedade, é fundamental nesse processo de fazer avançar a democracia no Brasil. Os movimentos sociais podem pedir o impossível, mas, como diz Max Weber, às vezes só pedindo o impossível se consegue o possível. Acho que essa é uma contribuição fundamental. 